DOI 10.37882/2223-2982.2021.08.09

\title{
ОБ ИНФОРМАЦИОННЫХ БЛОКАХ В ПРОФЕССИОНАЛЬНО- ОРИЕНТИРОВАННЫХ ТЕКСТАХ ДЛЯ ОБУЧЕНИЯ ДИЗАЙНУ
}

\section{ABOUT INFORMATION BLOCKS IN PROFESSIONAL-ORIENTED TEXTS FOR LEARNING DESIGN}

\section{E. Demidova}

Summary: The text part of a professional thematic site for design is interesting from a scientific point of view, since it is multifunctional, informative and clearly structured. A professionally oriented text has a lexical (linguistic), logical and grammatical basis, organized in a certain way in order to convey information.

The functioning of the language on a web page is due to the principle of hypertext. Hypertext is intended to make the document more understandable and convenient to use, to simplify the process of accessing data and, as a result, to ensure successful professional communication. It gives the website convenience and logical structure of content, useful functions for the user, the inclusion of media elements for a variety of content. In the structure of a professional website for designers, we observe the following information blocks: text content, information in the header and footer of the site; calls to action; pop-ups; advertisements about work with the site; information blocks on product cards; blocks in the sidebar.

The text part of the studied websites (about 50) has the following characteristics: uniqueness (originality and originality of the content), optimization for search queries (keywords in texts for search robots). The authors of the textual part of the website, using professional vocabulary, verbalize the following concepts of the professional reality of a designer: "Advantages of the profession of a designer", "Disadvantages of the profession of a designer", "Directions of design", "Duties of a designer", "Professional skills of a designer", "Personal qualities of a designer".

Keywords: web design, hypertext, professional communication, dialogicity, dynamism, typography.

\author{
Демидова Евгения Владимировна \\ К.филол.н., дочент, ФГБОУ ВО «Пятигорский \\ государственный университет» \\ eva.demidova.85@list.ru
}

Аннотация: Текстовая часть профессионального тематического сайта для дизайна интересна с научной точки зрения, так как она многофункциональна, информативна и четко структурирована. Профессионально-ориентированный текст имеет лексическую (языковую), логическую и грамматическую основы, определенным образом организованные с целью передачи информации.

Функционирование языка на веб-странице обусловлено принципом гипертекста. Гипертекст призван сделать документ более понятным и удобным в использовании, упростить процесс доступа к данным и как следствие, обеспечить успешную профессиональную коммуникацию. Он дает веб-сайту удобство и логичное структурирование контента, полезные функции для пользователя, включение элементов медиа для разнообразного контента. В структуре профессионального сайта для дизайнеров, мы наблюдаем следующие информационные блоки: текстовый контент, информация в шапке и подвале сайта; призывы к действию; поп-апы; объявления о работе с сайтом; инфоблоки на карточках товаров; блоки в сайдбаре.

Текстовая часть исследуемых веб-сайтов (около 50) обладает следующими характеристиками: уникальность (оригинальность и неповторимость контента), оптимизирование под поисковые запросы (ключевые слова в текстах для поисковых роботов).

Авторы текстовой части веб-сайта при помощи профессиональной лексики вербализуют следующие концепты профессиональной реальности дизайнера: «Преимущества профессии дизайнера», «Недостатки профессии дизайнера», «Направления дизайна», «0бязанности дизайнера», «Профессиональные навыки дизайнера», «Личностные качества дизайнера».

Ключевые слова: веб-дизайн, гипертекст, профессиональная коммуникация, диалогичность, динамичность, типографика.
Д анное исследование посвящено изучению лингвокогнитивных особенностей структуры информационного пространства профессионально-ориентированных веб-сайтов, адресованных дизайнерам.

Исследуемый вид текста интересен с научной точки зрения, так как он является многофункциональным, чрезвычайно информативным, емким, четко структурированным. Как и любой другой текст, он имеет лексическую (языковую), логическую и грамматическую основы, определенным образом организованные с целью передачи информации.
В рамках данной статьи мы предпринимаем попытку проанализировать структуру информационного пространства англоязычного веб-сайта для профессионального обучения дизайну, взаимодействие определенных информационных блоков в тексте, механизмы передачи и восприятия профессионального знания в тексте.

В современное время, в связи с увеличением спроса на представительство в сети, растет спрос и на качественный дизайн сайтов. Также увеличивается количество веб-дизайнеров, вовлеченных в эту работу. Веб-дизайн - это вид графического дизайна, который направлен на разработку и оформление объектов инфор- 
мационной среды, призванный обеспечить им высокие потребительские и эстетические свойства. Основным объектом для работы веб-дизайнера является веб-сайт.

Специалисты выделяют несколько типов вебдизайна: текстовый дизайн (внимание уделяется содержанию, изображения играют декоративную роль), полиграфический дизайн (пиксельная графика), интерфейсный дизайн (оптимизация изображений), динамический дизайн (художественный образ), смешанный дизайн (сочетание нескольких видов дизайна) (Вид дизайна. URL: https://reclamare.ua/blog). В рамках этой статьи мы рассмотрим подробно текстовый дизайн.

Сосредоточим наше внимание на главном рабочем объекте веб-дизайнера - веб-сайте. Веб-сайт (website: web - «паутина, сеть» и site - «место, сегмент, часть в сети») определяют как одну или несколько логически связанных между собой веб-страниц; место расположения контента сервера; массив связанных данных, имеющий уникальный адрес и воспринимаемый пользователями как единое целое. Веб-сайт определяют также как систему электронных документов, принадлежащую частному лицу или организации, доступную в компьютерной сети под общим доменным именем и IP-адресом (Атабекова А.А. Лингвистический дизайн Web-страниц. М. 2002. С. 11). Страницы сайтов - это определенная система текстовых файлов, размеченных на языке HTML, который позволяет создавать гипертекстовые ссылки и вставлять в отображаемую страницу мультимедийные элементы. Таким образом, веб-сайт есть совокупность документов с гипертекстовой информацией, доступной в Интернете (Городецкий Б.Ю. Компьютерная лингвистика: моделирование языкового общения. Новое в зарубежной лингвистике. М. 1989. С. 5-32), (Городецкий Б.Ю., Кобозева И.М., Сабурова И.Г. К типологии коммуникативных неудач. Диалоговое взаимодействие и представление. М. 1985. С. 42).

Поэтому веб-дизайн - это процесс создания сайтов, состоящий из технической разработки, создания удобной структуры веб-страницы, графического оформления и передачи информации в сеть. Специалист по вебдизайну разрабатывает макет, работает над графикой сайта и его интерфейсом. Основные элементы работы в процессе создания дизайна веб-сайта - это графическое редактирование, колористика и типографика (Городецкий Б.Ю., Кобозева И.М., Сабурова И.Г. К типологии коммуникативных неудач. Диалоговое взаимодействие и представление. М. 1985. С. 42).

Деятельность веб-дизайнера нередко сравнивают с работой архитектора, разрабатывающего план дома. Веб-дизайнер превращает идею заказчика в визуально привлекательный дизайн, а именно создает макеты, строит интерфейс и разрабатывает определенный сценарий коммуникации клиента с сайтом. Работа вебдизайнера всецело связана с пошаговой и детальной разработкой веб-сайта.

\section{Обзор литературы}

С точки зрения лингвистики, в процессе веб-дизайна идет многоуровневая работа над структурой текста и его стилем на веб-сайте (Дускаева Л.Р. Диалогическая природа газетных речевых жанров. С.- Пб. 2004. 26 с). Актуальность данной статьи обусловлена тем, что коммуникация с пользователем сайта играет в дизайне огромную роль и требует тщательного изучения. Роль текста в вебдизайне является ключевой, так как грамотность текста обеспечивает читабельность сайта (Куликова Е.В. Графические средства как стилистические приемы художественного текста. 2000. С. 6). Помимо информационного наполнения текст сайта обладает также графическими возможностями для формирования эстетического восприятия веб-сайта.

Ю.В. Потехина описывает работу веб-дизайнера следующим образом: он выполняет широкий спектр работ, самостоятельно выполняет каждый этап разработки сайта и осуществляет его дальнейший запуск (lamtiredonline. URL: https://iamtiredonline.com/). Тем не менее, веб-дизайнер сам контролирует весь процесс создания будущего проекта. Объем, содержание и форму текста сайта диктует специфика веб-сайта и дизайнерское решение (Типографика. URL: https://ia.net/ topics/the-web-is-all-about-typography-period/).

Крепкая связь между веб-сайтом и пользователем помогает ему впоследствии в достижении поставленных целей (Городецкий Б.Ю. Компьютерная лингвистика: моделирование языкового общения. Новое в зарубежной лингвистике. М. 1989. С. 5-32). Профессионально-ориентированные веб-сайты предназначены для деловой коммуникации (извлечения необходимого профессионального знания и достижения определенных задач в профессиональном сообществе) (Ширяева Т.А., Авшаров А.Г. Социокогнитивное моделирование как методологическая основа изучения делового дискурса. М. 2018. С. 94). Чтобы изучить и понять задачи профессионального делового сообщества, по мнению зарубежных исследователей, необходимо принимать во внимание специфику контекста, включающую деловую стратегию, деловую среду (Дускаева Л.Р. Диалогическая природа газетных речевых жанров. С.- Пб. 2004. 26 с). Участники сообщества понимают, что обмен знаниями - это необходимое условие для развития успешной деятельности. Основную коммуникативную функцию на веб-странице выполняет текст (Куликова Е.В. Графические средства как стилистические приемы художественного текста. 2000. С. 6).

Согласно Б.Ю. Городецкому, на пространстве веб- 
страницы осуществляется концептуализация знаний ее пользователем. В процессе прочтения текста пользователь извлекает из текста некоторую совокупность знаний и перерабатывает, осмысливает и вербализует, где категория знания является ключевой, объединяющей эти два процесса (Городецкий Б.Ю., Кобозева И.М., Сабурова И.Г. К типологии коммуникативных неудач. Диалоговое взаимодействие и представление. М. 1985. С. 42). Их успешность характеризует удачную коммуникацию, а «затрудненное понимание» (Пешковский. Избранные труды. М, 1959, С. 10), влечет за собой коммуникативную неудачу.

В ряде лингвистических исследований коммуникативный дискомфорт (определение Е.М. Мартыновой) (Мартынова Е.М. Типология явлений коммуникативного дискомфорта в ситуациях диалога. М. 2000. 229 с), (Городецкий Б.Ю. Компьютерная лингвистика: моделирование языкового общения. Новое в зарубежной лингвистике. М. 1989. С. 5-32) рассматривается в связи с личностными характеристиками коммуникантов, обстоятельствами общения, трудностями достижения коммуникативных целей, нарушением принципа коммуникативной контактности.

Многие исследователи языка (Б.Ю. Городецкий, И.М. Кобозева, И.Г. Сабурова) считают, что функционирование языка на веб-странице в процессе подготовленной письменной дистантной коммуникации в сети Интернет обусловлено принципом гипертекста, основой технологии существования Сети (Городецкий Б.Ю., Кобозева И.М., Сабурова И.Г. К типологии коммуникативных неудач. Диалоговое взаимодействие и представление. М. 1985. С. 42). На пространстве веб-страницы существуют основной линейный текст и высказывания-микротексты (гиперссылки).

Гиперссылки используются для обозначения блоков информации, размещенные на других страницах сайта. Виртуальность и дистантный характер коммуникации, принцип сетевого размещения данных, возможность создания текстовых массивов разными авторами требует избирательного использования выразительных средств языка для построения высказываний. Гипертекст призван сделать документ более понятным и удобным в использовании, упростить процесс доступа к данным и как следствие, обеспечить успешную профессиональную коммуникацию (Трофимова Ю.М. Лингвистические и экстралингвистические проблемы коммуникации. Мордовия, 2003. С. 192).

Профессиональная коммуникация, которая осуществляется посредством веб-сайта, является непременным условием эффективного взаимодействия и обмена профессиональным опытом. Она играет роль определенного посредника между дизайнером, его коллегами и создателем сайта (Типографика. URL: https://deadsign.ru/ tipografika/10_tips_on_typography/).

Гипертекст дает веб-сайту определенные возможности: удобство и логичное структурирование контента, полезные функции для пользователя, включение элементов медиа для разнообразного контента. Чтобы получить информацию, пользователю достаточно нажать на выделенный элемент (Атабекова А. А. Лингвистический дизайн Web-страниц. М. 2002. C. 11).

Гипертекст в лингвистике - это текст, устроенный таким образом, что он превращается в систему, иерархию текстов, одновременно составляя единство и множество текстов. Благодаря публикациям последних лет гипертекст в целом и электронный гипертекст в частности стал самостоятельным и полноправным объектом лингвистического исследования в работах О.В. Барст, М. Визеля, Е.И. Горошко, К.В. Давыдовой, О.В. Дедовой, А.А. Залевской, Е.В. Зыковой и многих других исследователей.

Теоретический анализ литературы показывает, что среди понятий «книжный гипертекст», «квазигипертекст», «книжный (печатный) художественный гипертекст», немаловажным является понятие «электронный гипертекст». «Электронный гипертекст» определяют как нелинейно организованный объем поликодовой информации, обладающий текстовыми характеристиками, структурными и функциональными особенностями, интегрирующий непересекающиеся информационные ресурсы, между которыми могут быть установлены однонаправленные и перекрестные ссылки. Текстовые ссылки автор обычно выделяет другим цветом или подчеркивает.

А.Н. Федоренко придерживается точки зрения, что профессиональная коммуникация - это профессионально обусловленный процесс обмена информацией (знанием) между представителями одной профессии, направленный на профессиональное развитие, в ходе которого создаются профессиональные сообщества, характеризующиеся определенными нормами мышления, поведения и взаимодействия между членами сообщества. Это коммуникация служит для передачи профессиональных знаний и умений (Федоренко. Профессиональная коммуникация. URL: https://sfk-mn.ru/ PDF/01SFK417.pdf).

Самым востребованным информационным условием для профессионального общения является интернет глобальная информационная и коммуникационная среда, мобильность, электронные представительства, сервисы, веб 2.0, социальные медиа (Canva.ru. URL: https:// canva.com/ru/).

В нашем исследовании мы определяем профессио- 
нальное сообщество как группу людей, состоящую из двух и более человек, регулярно вступающих в личное или виртуальное коммуникативное взаимодействие друг с другом с целью обмена практическим опытом и концептуализации новых профессиональных знаний.

Английский язык в сфере профессиональной коммуникации является модернизированным и упрощенным вариантом английского языка в целом, для которого характерно наличие стандартных фраз-клише, а также всевозможных шаблонов. Он является наиболее популярным языком профессионального общения. Текстовая и гипертекстовая часть представляется нам наиболее интересной для исследования.

На электронных ресурсах реализуется информационная функция делового общения. Мотивационная функция профессиональной коммуникации состоит в том, что электронный ресурс мотивирует начинающего веб-дизайнера более качественно выполнять стоящие перед ними задачи.

В современном обществе цифровые коммуникации - это «способ построения коммуникаций компании с потребителями, осуществляемый на основе технологий» (Федоренко. Профессиональная коммуникация. URL: https://sfk-mn.ru/PDF/01SFK417.pdf).

Цель нашей статьи - изучить особенности структурирования профессиональной информации на англоязычных профессиональных веб-сайтах для дизайнеров.

Актуальность данной статьи обусловлена тем, что коммуникация с пользователем сайта играет в дизайне огромную роль и требует тщательного изучения (Городецкий Б.Ю. Компьютерная лингвистика: моделирование языкового общения. Новое в зарубежной лингвистике. М. 1989. С. 5-32). Роль текста в веб-дизайне является ключевой: грамотно написанный текст обеспечивает читабельность сайта. Профессионально-ориентированные веб-сайты предназначены для деловой коммуникации (извлечения необходимого профессионального знания и достижения определенных задач в деловом сообществе) (Ширяева Т.А., Авшаров А.Г. Социокогнитивное моделирование как методологическая основа изучения делового дискурса. М. 2018. С. 94). Чтобы изучить и понять задачи делового сообщества, по мнению зарубежных исследователей, необходимо принимать во внимание специфику контекста, включающую деловую стратегию, деловую среду (Дускаева Л.Р. Диалогическая природа газетных речевых жанров. С.- Пб. 2004. 26 с). Основную коммуникативную функцию на веб-странице выполняет текст (Куликова Е.В. Графические средства как стилистические приемы художественного текста. 2000. С. 6).

Информация как на любом сайте, так и на професси- ональном сайте размещается в определенных «информационных блоках» (Валгина Н.С. Теория текста. М. 2003. ( 3). Веб-дизайнеры используют это понятие для блоков на сайте, содержащих информацию, для текстового контента и всплывающих окон (Трофимова Ю.М. Лингвистические и экстралингвистические проблемы коммуникации. Мордовия, 2003. С. 192). В нашей статье мы берем за основу элементы сайта в качестве информационного блока. На них размещается информация для пользователей о деятельности компании, условиях покупки, доставки или оплаты (Типографика. URL: https://ia.net/ topics/the-web-is-all-about-typography-period/).

Нами был проведен лингвистический обзор текстовой составляющей самых успешных профессиональных веб-сайтов, адресованных дизайнерам на английском языке 2019-2021 годов в сети Интернет. По версии Awwwards, список самых успешных сайтов 2019-2020 годов включает Stock Photography Then and Now [13] от креативного агентства ADVANCED TEAM (обзор эстетики и истории стоковой фотографии за последние 10 лет).

Проанализировав структуру профессионального сайта для дизайнеров, мы наблюдаем определенную подачу информации информационных блоков, которую можно классифицировать следующим образом:

1. Текстовый контент (блок, состоящий только из текста; описание профессиональных инструментов веб-сайта) (Awwwards. URL: https://awwwards.com/);

2. Информация в шапке и подвале сайта (контактные данные, иконки с корзиной);

3. Призывы к действию (информация о повышении квалификации);

4. Поп-апы (всплывающие окна с информацией об акциях компании и веб-формами для заказа);

5. Объявления о работе с сайтом (информация о технических неполадках);

6. Инфоблоки на карточках товаров (описание условий покупки программ, приложений для дизайнеров);

7. Блоки в сайдбаре (элементы, расположенные на боковых панелях сайта) (Canva.ru. URL: https:// canva.com/ru/).

Для анализа текста нами были использованы методы сбора фактического материала, описательный и структурный методы с использованием материалов с англоязычных веб-сайтов для дизайнеров. В результате анализа мы выделяем наиболее популярные темы: review of worldwide design works (обзор дизайнерских работ по всему миру), challenges (конкурсы), experience (обмен опытом), registration (регистрация), invite from a frienddesigner (специальное приглашение от друга-дизайнера). Они, как правило, оформлены в гипертекстовые ссылки или рубрицированы (заголовки, тезисы) (Fleava. URL: https://fleava.com/). 
Например, на стартовой странице сайта Land-book. com заголовок оформлен более крупным шрифтом и оформлен в особой цветовой гамме: Grab a popcorn. The new Land-book is ready. Далее идет раздел Lead-in: We're super excited to introduce you to our brand new gallery! We reinvented it from top to bottom (здесь шрифт меньшего размера, другой регистр). Вся информация разделена графически и логически на смысловые информационные блоки: рубрики и секции (gallery, my favs); подсекции (all landings, portfolios, blogs, stories, others templates). В $65 \%$ от общего количества исследуемых сайтов присутствуют информационные блоки с портфолио начинающих и известных дизайнеров для просмотра, обмена опытом, облегчения поиска работы и контакта с работодателем (Типографика. URL: https://deadsign.ru/tipografika/10_ tips_on_typography/).

\section{Приведем пример:}

Peter Demulsant - Interactive developer. http:// picodix.me/PortfoliosTech, Personal, Design, Light Colors, Dark Colors, Big Type. My name is Peter and I am currently living in France. Get in my mood. Experience. 2019/2018/2017/2016.

Building sharp interfaces and interactive experiences on the web for various clients across the world. Constantly learning and trying out new tools and techniques. Senior Interface Developer at Heyday. Part of the frontend team to build and maintain websites and platforms for clients like Mitsubishi, Garage Project, Z Energy... I also focused on processes, documentation and onboarding developer experience (блок содержательно-фактуальной информации).

Interests: always keen for a good beer, so feel free to say hello. When I am not working, I have others passions I dive into like drone flying and aerial imagery from countries I've had the chance to travel to. Check out my Instagram (блок эмотивно-окрашенной информации о личностных качествах дизайнера).

Hey Land-bookers! Leave your email to get the most recent websites inspirations right in your inbox. No spam. Ever (блок обратной связи с посетителем сайта).

На сайте Web Design Inspiration также информация рубрицирована: Inspirations, Editor's Pics, Word Press, Themes, Blogs. Вводная статья разбита на абзацы, заголовки выделены жирным шрифтом, каждый раздел имеет уникальный шрифт, цвет и анимацию (Design. URL: https://dic.academic.ru).

Our mission is: what you need is a web design that will appeal to your target audience, drive traffic to your business, and increase sales, then we recommend you to get a lot of inspiration : it can be colors, typography, branding, ux design, fonts, ecommerce, new trends. You do need a way to get the last web design trends

\section{WHO IS WEB DESIGN INSPIRATION}

Web design Inspiration is an agency that operates in such a way that it provides best of web designs, website templates of graphic designers, on its web page. These website templates, designs serve as a means of inspiration to creatives, newbies or either intermediate/expert website developers, graphic designers out there.

The graphics used such as logos, icons are of top quality from skilled graphic designers all over the world. This graphics and logos play a vital role in whatever website you want to create. With a logo, icon designed gives whatever targeted audience of any niche insights about what the brand entails (Fb.ru. URL: https://fb.ru/article/448319/).

Сайт Designshack.net имеет аналогичное структурирование профессиональной информации: рубрикация Search Design Shack (поисковая строка), Articles (статьи на профессиональные темы), Gallery About (фотоработы), 5 Tips for Working With Design Influencers (профессиональные советы):

Slab serif fonts can be used for a variety of purposes, ranging from general body text to headlines, to display copy. It's a typography variant that has been used widely for digital as well as print purposes, and devices such as Amazon Kindle even use a slab serif as their default font (Дизайн. URL: https:// reclamare.ua/blog).

Для данных профессиональных сайтов Рубрика профессиональных объявлений характерна и частотна: Children Book. I am Looking for an illustrated children's book designer. This will be seven pages including the cover book.

SaaS Product SVG Illustrations. We're a software company looking for a skilled illustrator for the designs on our new marketing pages.

Очевидно, что авторы текстовой части веб-сайта вербализуют при помощи профессиональной лексики следующие концепты профессиональной реальности дизайнера:

- «Преимущества профессии дизайнера»: востребованность профессии, высокая зарплата, гибкий график, творческая работа;

- «Недостатки профессии дизайнера»: сложности выхода на хороший уровень оплаты, свободный график работы, нерегулярность заказов, субъективность оценки работы;

- «Направления дизайна»: дизайн интерьеров, вебдизайн (структура и тематика сайта, графический дизайн (создание логотипов, фирменного стиля, навигационных систем), ландшафтный дизайнер (создание ландшафта парков, скверов и приусадебных участков), проекты для производства; 
- «Обязанности дизайнера»: создание конструкций и разработка изображения моделей интерьера, мебели, аксессуаров, компьютерной графики, ландшафта;

- «Профессиональные навыки дизайнера»: владение классическими и нетрадиционными техниками графики и рисования; знание основ компьютерного дизайна, программ SketchUp, AutoCAD, ArchiCAD, Sweet Home 3D; владение навыками айдентики, экономики и маркетинга проекта; знание второго языка;

- «Личностные качества дизайнера»: логическое мышление (создание реальных проектов, концептуальное и логическое мышление, индивидуальный стиль (генерирование уникальных идей, внимательность (точность в составлении проекта интерьера, корректное составление макета веб-дизайна), усидчивость (ограничение работы дедлайном), наблюдательность, хорошее воображение, умение нестандартно мыслить, коммуникабельность (Веб-дизайн. URL: https://start-luck.ru/ dlya-novichka).

По мнению Оливера Райхенштайна в статье «Вебдизайн на 95\% состоит из типографики» (Веб-дизайн. URL: https://blog.depositphotos.com/ru/luchshie-dizajnisajtov-2020.html/). Типографика - сильнейший инструмент для выражения посыла в веб-дизайне, объединяющий текстовую и визуальную составляющие; свод законов, правил и норм оформления текста, основанных на изучении восприятия набора читателем. Знание и понимание типографики превращают текст в инструмент построения композиции, делают его живым, придают характер и способность передать идею не только при помощи содержания, но и графически. Типографика, в нашем понимании, есть наука об эргономике текста. Изучая веб-страницу, мы обращаем наше внимание на гарнитуру (шрифт), антикву - шрифты с засечками, гротеск - шрифт без засечек (акцентирует рациональность, следование стилю); помогает создать пространство между буквами. Кегль (высота буквы, включающая в себя нижние и верхние выносные элементы), интерлиньяж (межстрочный интервал), кернинг (расстояние между буквами) дают возможность увеличения удобочитаемости путем подбора интервалов между буквами.

Разделение текста на абзацы также делает его удобным для прочтения (Пешковский. Избранные труды. М, 1959, С. 10). Наш анализ достоверно демонстрирует, что выравнивание текстового блока традиционно на вебсайте происходит по левому краю в 85 \% блоков. Если текстовые блоки выравнивают по ширине, по центру, по правому краю, то текст не доступен для визуального восприятия.

Основные темы (обзор дизайнерских работ по всему миру, конкурсы, обмен опытом, условие работы на сайте, регистрация и специальное приглашение (invite) от друга-дизайнера) оформлены в гипертекстовые ссылки или рубрицированы (заголовки, тезисы).

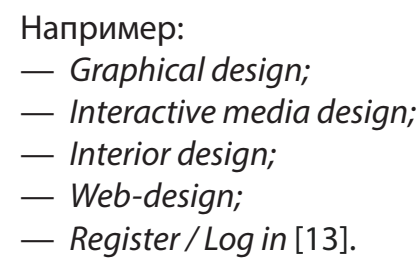

Ресурс Awwwards.com, Designshack.net (анализ проектов), Behance.net (социальная сеть для дизайнеров), Mobbin.design (приложения и шаблоны), Webdesign-inspiration.com (выставка работ дизайнеров), Bestwebsite. gallery (проекты и портфолио дизайнеров) размещают свою информацию в размерах одной страницы. Вся необходимая информация размещается на одностраничных ресурсах, чтобы не перегружать страницу текстом.

В текстовой части информация представляется в процессе взаимодействия с адресатом веб-сайта, присутствует референция, подчеркивается реальность информации, обозначается равнозначность фрагментов информации. Взаимодействие высказываний-гиперссылок с лексической и грамматической структурой разного наполнения способствует логической коммуникативной организации гипертекста как специфического речевого произведения в среде электронного общения.

Текстовая часть исследуемых веб-сайтов (около 50) обладает следующими характеристиками: уникальность (оригинальность и неповторимость контента), оптимизирование под поисковые запросы (ключевые слова в текстах для поисковых роботов). Наиболее частотными комбинациями слов на сайте являются: design, web-design, videolphoto files, content, typography, resource (50\%); project, work, usability, creativity, innovation, content, cast, podcast, font, colour, tools, apps (20\%); winner, nominee, blog, vlog, display, typeface (15\%); highlight, event, recycling, host, photo host, video host (15\%). Это позволяет точно определять тематику и направленность сайта, чтобы впоследствии выводить их как наиболее релевантные результаты для членов профессионального сообщества. Тексты, представленные на изучаемых нами сайтах всегда информативны и актуальны с целью привлечения внимания пользователей-членов профессионального сообщества, которые будут обращаться к информационному ресурсу вновь.

В сети Интернет существуют сотни дизайнерских вебсайтов для обучения, но самыми популярными и востребованными, а также интересными с лингвистической точки зрения для нас являются: https://dribbble.com/ (веб-портал для дизайнеров), https://www.behance.net/ - 
(веб-сайт для дизайнеров, иллюстраторов, художников, фотографов, видеографов, архитекторов), http://revision. ru/ (сетевой выставочный зал), https://land-book.com/ (сайт-портфолио), https://www.awwwards.com/ - (вебдизайна и разработка сайтов), http://www.webdesigninspiration.com/ (ресурс для работы с фильтрами и цветами), https://www.thebestdesigns.com/ (каталог работ в сфере веб-дизайна), https://ru.pinterest.com/, https://pttrns.com/ - сайт с шаблонами интерфейса на любой вкус, https://unsplash.com/ - (сайт мировых фоторабот), http://www.lifeofvids.com/ (сайт видеоработ), http://www.freepik.com/ (сайт графических ресурсов для дизайнеров) и многие другие.

Проведя обзор профессиональных веб-сайтов для дизайнеров, мы выделяем следующие их типы:

- сайты о дизайне в целом, например, такие как https://dribbble.com/ (веб-портал для дизайнеров); https://www.behance.net/ - (веб-сайт для дизайнеров, иллюстраторов, художников, фотографов, видеографов, архитекторов);

- сайты, где представлены портфолио дизайнеров и выставка их работ, ознакомление с творчеством; фотобанки, коллекции цветовых сочетаний, шрифтов. Например: http://revision.ru/ (сетевой выставочный зал), https://land-book.com/ (сайтпортфолио), https://unsplash.com/ - (сайт мировых фоторабот), http://www.lifeofvids.com/ (сайт видеоработ), http://www.webdesign-inspiration.com/ (ресурс для работы с фильтрами и цветами);

- сайты об организации работы в дизайне для руководителей для фриланса как организовать и направить команду тим-билдинг https://www. awwwards.com/ - (веб-дизайна и разработка сайтов), https://www.thebestdesigns.com/ (каталог работ в сфере веб-дизайна);

- сайты-онлайн-магазины, где найти все необходимое оборудование и материалы для практической прикладной работы в дизайне;

- сайты графических ресурсов для дизайнеров: https://ru.pinterest.com/, https://pttrns.com/ (сайт с необходимыми шаблонами интерфейса), http:// www.freepik.com/ и многие другие;

- сайты - собрание всех медиаресурсов в дизайне: https://unsplash.com/ - (сайт мировых фоторабот), http://www.lifeofvids.com/ (сайт видеоработ);

- сайты, сфокусированные на чем-то конкретном (логотип, узор, стиль);

- сайты, специализирующиеся на работе в какойто конкретной платформе, такие как Flex Adobe: blogs.adobe.com - блог графического дизайнера Джона Нэка (John Nack);

- сайты о типографике текста на веб-сайте.

Самые популярные именные блоги дизайнеров, посвященные всем аспектам дизайна: blogof. francescomugnai.com (вдохновляющий и эстетичный блог итальянского дизайнера Francesco Mugnai), lysergid. com - (хороший французский блог о повышении качества статей, свежем дизайне), blog.iso50.com - популярный блог графического дизайнера Скотта Хэнсена, blogs. adobe.com - блог графического дизайнера Джона Нэка.

По внешнему виду оформления самым популярным является следующий вид сайтов: promo website. Он выглядит как сайт-визитка компании или организации. Такой веб-сайт часто представлен в виде одной страницы, на которой представлена вся нужная информация. Профессиональные веб-сайты не являются исключением. Оформление в виде сайта-визитки также чрезвычайно популярно для дизайнерских веб-сайтов. Веб-дизайнер осуществляет большой объем работы и выполняет определенные правила, чтобы вместить весь необходимый контент на одну страницу и не отвлекать внимание клиента на незначительные детали.

Хорошим примером является промо-веб-сайт компании BMW. Информация на этом сайте помещается в пределах одной страницы. Сайт имеет гармоничное цветовое оформление: черный, красный, белый цвета. Всплывающее меню навигации знакомит пользователя с разделами на сайте: Test-drive, Characteristics, Overview BMW X6, Dealers, Configuration, Contacts. По центру вебстраницы представлена иллюстрация модели BMW X4 XDrive 30 D и ее технические характеристики (мощность двигателя, максимальная скорость, расход топлива на 100 км, дизайн кузова).

Существуют определенный регламент структуры веб-сайта, его неотъемлемые элементы, которые задают структурированность, гармоничность и логику информации на сайте. Проведя анализ структуры веб-сайтов для дизайнеров, мы наблюдаем присутствие следующих элементов веб-сайта:

- flyout navigation - это всплывающее меню навигации, которое содержит несколько ссылок на разные страницы или разделы на веб-сайте. Подобное меню содержит несколько столбцов. Раскрывающееся меню отображает, как правило, один столбец под главной вкладкой;

- above the fold (верхняя полоса) - ключевое определение для людей, работающих с онлайн-платформами. Для веб-дизайнеров, это термин означает часть экрана, где размещается основной контент, так как его будет видно полностью и без прокрутки вниз;

- style tiles - четкий структурный стиль, характерный для сети Pinterest. Основа данного стиля: структура, которая состоит и колонок и паралелльно, но не симметрично подается материал в виде плиток, оформление плиток в разных размерах, эстетичное оформление. 
- metro - метро-интерфейс, так называемый «дизайнерский язык Microsoft», был разработан Microsoft и сегодня используется во многих продуктах этой компании. Швейцарский стиль - основа дизайна Metro. B Microsoft называют стиль «простым и современным». Характерная черта стиля Metro - это акцент на крупном тексте, привлекающем внимание и высококачественная типографика.

- texture - текстуры являются хорошим способом для экспериментов. Использование текстуры может стать отличным способом для разнообразия дизайна, придания тонкости дизайну или для акцентов в дизайне

Hero - это общий термин, который используется для обозначения основного изображения на домашней или целевой странице. На профессиональных веб-сайтах для дизайнеров как правило несколько основных изображений. Логотип создателя этого тренинга, обучающего сайта,

Mockup - это макет, который демонстрирует, как будет выглядеть будущий сайт. Отличие макета от реального сайта только в том, что макет не функционирует. На профессиональных веб-сайтах мы, как правило, встречаем образцы макетов для разных профессиональных целей.

Negative space - негативное пространство или попросту «белые пятна»: термин, который означает свободную область, которая не занята содержанием и образуется между различными элементами на страничке. Термин «негативное пространство» одним из первых стал употреблять американский художник-оформитель Чарли Гослин. В его работах до сих пор многие дизайнеры находят вдохновения для своих работ. Негативное пространство может грамотно конкурировать с позитивным пространством в дизайне или выигрышно поддерживать его. Основная задача негативного пространства - не отвлекать внимание от основного содержания.

Flat design - пример плоского дизайна, частотный для многих профессиональных веб-сайтов. В основе этого дизайна лежит простота и функциональность, отсутствие объема у элементов. В них отсутствуют техники, придающие объемность и глубину: нет градиентов, теней, текстур, бликов. В плоском дизайне используются основы графики - яркие цвета, простые формы кнопок и иконок.

Favicon - (сокр. от англ. FAVorites ICON) - значок сайта, который отображается браузером в адресной строке перед URL страницы и в качестве иконки к закладке и в других элементах интерфейса.

Авторы профессиональных веб-сайтов для дизайнеров рекомендуют своим клиентам использовать для своих будущих сайтов адаптивный дизайн (responsive web design). Обучающие веб-страницы сами представляют собой адаптивные странички, с легкостью подстраивающиеся под различные устройства и дающие отличное восприятие, для каждого посетителя. Не зависимо от устройства, разрешения и формата экрана сайт, выполненный в адаптивном дизайне, всегда будет выглядеть удобно и презентабельно для любого пользователя.

Свои советы и рекомендации автор на сайте оформляет в виде руководства по стилю (Style guide). Руководство по стилю включает все цвета, шрифты и рекомендации по брендингу для веб-сайта.

Руководство по стилю часто является отличной подсказкой для веб-разработчика, облегчая техническую характеристику дизайна. Это также может сэкономить время разработчикам, и избавит от необходимости обращаться к веб-дизайнеру.

Наше исследование показывает, что 95 \% анализируемых сайтов наделены функцией rollover.

Rollover - это действие, которое происходит, когда пользователь наводит указатель мыши на определенный элемент, к которому применен эффект ролловера. Действие мыши вызывает изменение внешнего вида элемента в другое изображение, цвет или стиль шрифта.

Частотным явлением оказывается гармония и соотношение шрифтов на сайте. Веб-дизайнер иногда работает с несколькими шрифтами и подбирает размеры шрифтов друг другу с точки зрения ширины букв. Наиболее частотны системные шрифты (Arial, Calibri, Trebuchet). Также присутствует определенная закономерность в подборе количества знаков на одной строке: каждая строка содержит в среднем не более 60 знаков.

Цвет текста и фона всегда различаются на сайте. Серый или пастельный текст на сером фоне не всегда выразителен для посетителя. Поэтому частотным и экспрессивным является контраст цвета и текста: черный и белый (45\% сайтов), синий и белый (55\%). Чем меньше шрифт, тем более он контрастный.

Форматирование (заголовки, подзаголовки, абзацы, маркированные списки, оптимальная длина которых составляет 3-5 строк) объединяет 75\% текстовой части нашей выборки сайтов.

Также на исследуемых сайтах наблюдается постепенный отказ от макетов с классической сеткой, так как успешным в современном веб-дизайне является применение эффекта сломанной сетки. Сетка на вебстранице сайта есть базовая структура, основа (скелет) дизайна из «невидимых» линий, на которых расположены элементы дизайна. Это связывает их в общую систему и рационально поддерживает композицию. Колонки 
- это основные составляющие каждой сетки и авторы текстов осознанно приходят к нарушению традиционной композиции текста на сайте [23].

Тексты, созданные на сайте агентства Fleava, созданы для вдохновения будущих дизайнеров (Fb.ru. URL: https://fb.ru/article/448319/). На сайте наблюдается анимационная рубрикация текста (рубрики About и Our Works). Рубрика About содержит приветственное сообщение рор-uр, всплывающее окно с информацией и чат (поддержка, общение со специалистом круглосуточно). Частотной для почти всех анализируемых сайтов, в том числе и Fleava, является функция scroll down, drag, tap, scroll для более комфортного восприятия профессиональной информации (функции динамичного прокручивания). На сайте присутствует возможность листания страниц (previous $\backslash n$ ext). Для оформления своего сайта его разработчики выбрали черный цвет, на котором размещается текст с классическим шрифтом Arial и в белом цвете. Также в оформлении сайта преобладают синий, черный цвета и цвет морской волны. Согласно психологии цвета в рекламе, маркетинге и бизнесе, цвет не только помогает получить более объективную информацию о продукте, но и оказывает мощное психологическое воздействие (Wpsovet. URL: https://wpsovet.ru/optimizaciya-i-ispravlenie/).

Для медиа-проектов Fleava наряду с черным цветом для вкладок с информацией используются темно-синие оттенки, которые согласно деловому этикету общения используются для проектов, где важна стабильность и надежность.

На сайте Web Design Inspiration также информация рубрицирована: Inspirations, Editor's Pics, Word Press, Themes, Blogs. Вводная статья разбита на абзацы, заголовки выделены жирным шрифтом, каждый раздел имеет уникальный шрифт, цвет и анимацию.

Our mission is: what you need is a web design that will appeal to your target audience, drive traffic to your business, and increase sales, then we recommend you to get a lot of inspiration : it can be colors, typography, branding, ux design, fonts, ecommerce, new trends. You do need a way to get the last web design trends

\section{WHO IS WEB DESIGN INSPIRATION}

Web design Inspiration is an agency that operates in such a way that it provides best of web designs, website templates of graphic designers, on its web page. These website templates, designs serve as a means of inspiration to creatives, newbies or either intermediate/expert website developers, graphic designers out there.

The graphics used such as logos, icons are of top quality from skilled graphic designers all over the world. This graphics and logos play a vital role in whatever website you want to create. With a logo, icon designed gives what ever targeted audience of any niche insights about what the brand entails (Fb.ru. URL: https://fb.ru/article/448319/).

Сайт Designshack.net имеет аналогичное структурирование профессиональной информации: рубрикация Search Design Shack (поисковая строка), Articles (статьи на профессиональные темы), Gallery About (фотоработы), 5 Tips for Working With Design Influencers (профессиональные советы):

Slab serif fonts can be used for a variety of purposes, ranging from general body text to headlines, to display copy. It's a typography variant that has been used widely for digital as well as print purposes, and devices such as Amazon Kindle even use a slab serif as their default font (Дизайн. URL: https:// reclamare.ua/blog).

Рубрика профессиональных объявлений характерна и частотна для данных профессиональных сайтов: Children Book. I am Looking for an illustrated children's book designer. This will be seven pages including the cover book.

SaaS Product SVG IIlustrations. We're a software company looking for a skilled illustrator for the designs on our new marketing pages (Evolution. URL: https://evolution.depositphotos.com/).

Очевидно, что авторы текстовой части веб-сайта вербализуют при помощи профессиональной лексики следующие концепты профессиональной реальности дизайнера:

- «Преимущества профессии дизайнера»: востребованность профессии, высокая зарплата, гибкий график, творческая работа (Fleava. URL: https://fleava.com/);

- «Недостатки профессии дизайнера»: сложности выхода на хороший уровень оплаты, свободный график работы, нерегулярность заказов, субъективность оценки работы (Fleava. URL: https:// fleava.com/);

- «Направления дизайна»: дизайн интерьеров, веб-дизайн (структура и тематика сайта, графический дизайн (создание логотипов, фирменного стиля, навигационных систем), ландшафтный дизайнер (создание ландшафта парков, скверов и приусадебных участков), проекты для производства (Skillbox. URL: https://skillbox.ru/media/ design/64_sayta); (Дизайн. URL: https://reclamare. ua/blog);

- «Обязанности дизайнера»: создание конструкций и разработка изображения моделей интерьера, мебели, аксессуаров, компьютерной графики, ландшафта. 
- «Профессиональные навыки дизайнера»: владение классическими и нетрадиционными техниками графики и рисования; знание основ компьютерного дизайна, программ SketchUp, AutoCAD, ArchiCAD, Sweet Home 3D; владение навыками айдентики, экономики и маркетинга проекта; знание второго языка (Fb.ru. URL: https://fb.ru/article/448319/).

- «Личностные качества дизайнера»: логическое мышление (создание реальных проектов, концептуальное и логическое мышление, индивидуальный стиль (генерирование уникальных идей, внимательность (точность в составлении проекта интерьера, корректное составление макета веб-дизайна), усидчивость (ограничение работы дедлайном), наблюдательность, хорошее воображение, умение нестандартно мыслить, коммуникабельность (Веб-дизайн. URL: https://start-luck.ru/ dlya-novichka).

В тексте следует описание личности дизайнер и список профессиональных требований к нему:

- Look for inspiration for designs outside the web (фоновые знания о дизайне);

- Knowledge of modern web technologies (знание современных веб-технологий);

Текстовая часть сайта тесно связана с иллюстративным материалом на сайте. В данном случае интерактивность коммуникации с пользователем сайта передает иллюстрация обезьяны. Иллюстрация обезьяны имеет некоторый интерактивный характер. В зависимости от рубрики, которую открывает пользователь, выражение лица обезьяны меняется, демонстрируя разные эмоции (радость, задумчивость, испуг, гнев, удивление), настраивая пользователя на определенный лад.

На сайте Flickr слоган Find your inspiration написан самым крупным шрифтом. Далее шрифтом помельче автор приводит еще один слоган: Join the Flickr Community, home to tens of billions of photos and 2 million groups. Caмым мелким шрифтом Start for free. В оформлении данного сайта мы наблюдаем адаптивный дизайн: активное использование анимации (изображена активная клавиша, предполагается, что пользователю нужно нажать на нее, чтобы получить дополнительную информацию). Фоновое изображение - постоянно меняющаяся анимация (изображения осеннего леса, пустыни, савана, морского побережья, ночной мегаполиса). Помимо эстетического удовольствия происходит знакомство с творческими работами авторов, поскольку иллюстрации являются не просто рисунками, а репродукциями картин известных художников, например: Bentlo by Ria Putziker, Tree and Morning Mist by Jos Buurmans. Пользователю предоставляется возможность можно найти необходимые профессиональные контакты, получить дальнейшую информа- цию, вдохновляться, общаться.

Hypebeast.com - модный журнал о дизайне и культуре, представляет собой сайт - интернет - магазин, представляющий модные аксессуары, одежда, книги, блокноты, электронные приборы, разрабатываемые дизайнерами, имеют уникальный крой, узор, фасон, дизайн (manarishi purples camo T-shirt, human-made shirt, Yoshimoto book. Рубрика Design содержит последние новости о разработке инноваций в брендах Fender, LEGO, MedicomToy. blogs.adobe.com - блог графического дизайнера Джона Нэка (John Nack). Полные, подробные статьи о графике и пакете Adobe.

Рубрикация позволяет сгруппировать информацию в определенные информационные блоки для логического разделения и осмысления информации, например рубрики: News Insights and Inspiration ResponsibilityAdobe Life и подрубрики: Insights and Inspiration, Creativity, Digital Trasformation, Trends and research, Future of Work, Leadership, Customer Stories, Events, Creativity.

\section{Зак^ючение}

Текстовая часть профессионального тематического сайта для дизайна интересна с научной точки зрения, так как она многофункциональна, информативна и четко структурирована. Профессионально-ориентированный текст имеет лексическую (языковую), логическую и грамматическую основы, определенным образом организованные с целью передачи информации.

Функционирование языка на веб-странице в процессе подготовленной письменной дистантной коммуникации в сети Интернет обусловлено принципом гипертекста. Гипертекст призван сделать документ более понятным и удобным в использовании, упростить процесс доступа к данным и как следствие, обеспечить успешную профессиональную коммуникацию (Wiki. URL: https://ru.wikipedia.org/wiki/Сайт/).

Гипертекст дает веб-сайту определенные возможности: удобство и логичное структурирование контента, полезные функции для пользователя, включение элементов медиа для разнообразного контента.

В структуре профессионального сайта для дизайнеров, мы наблюдаем следующие информационные блоки: текстовый контент, информация в шапке и подвале сайта; призывы к действию; поп-апы; объявления о работе с сайтом; инфоблоки на карточках товаров; блоки в сайдбаре (Canva.ru. URL: https://canva.com/ru/).

Текстовая часть исследуемых веб-сайтов (около 50) обладает следующими характеристиками: уникальность (оригинальность и неповторимость контента), оп- 
тимизирование под поисковые запросы (ключевые слова в текстах для поисковых роботов).

Авторы текстовой части веб-сайта вербализуют при помощи профессиональной лексики следующие концепты профессиональной реальности дизайнера: «Преимущества профессии дизайнера», «Недостатки профессии дизайнера», «Направления дизайна», «Обязанности дизайнера», «Профессиональные навыки дизайнера», «Личностные качества дизайнера».

Важный момент на сайтах для веб-дизайнеров - обеспечение подчиненности и взаимозависимости элементов. Каждый элемент должен был быть обоснован. Шрифт определенного размера, надпись конкретного цвета, графические символы - их выбор должен быть обоснован.

Плавные обтекаемые формы, отсутствие агрессии, спокойствие в оформлении компонентов, использование определенных цветов и оттенков цвета для целенаправленного воздействия на потребителя характерны для цветового оформления сайта. Анализ цветового оформления показывает, что наиболее частотными в оформлении данных сайтов являются красный - опасность, смелость; зеленый - умиротворенность, спокойствие, синий - легкость, свежесть, желтый - радость, положительная энергия; белый - чистота, доброта; черный - серьезность, стабильность, уверенность.

\section{ЛИТЕРАТУРА}

1. Александрова 0.В. Проблемы экспрессивного синтаксиса. - Москва: Высшая школа, 1984. - С. 7.

2. Атабекова А.А. Лингвистический дизайн Wеb-страниц. Монография - Москва, 2002.

3. Валгина Н.С. Теория текста: учебное пособие. - М.: Логос, 2003. -250 с.

4. Городецкий Б.Ю. Компьютерная лингвистика: прикладная лингвистика. // Новое в зарубежной лингвистике. Издание XXIV (компьютерная лингвистика). - М., 1989.

5. Городецкий Б.Ю., Кобозева И.М., Сабурова И.Г. К типологии коммуникативных неудач. // Диалоговое взаимодействие и представление знаний. Новосибирск, 1985. -42 с.

6. Городецкий Б.Ю., Кобозева И.М., Сабурова И.Г. К типологии коммуникативных неудач. // Диалоговое взаимодействие и представление знаний. Новосибирск, 1985. -42 с.

7. Дускаева Л.Р. Диалогическая природа газетных речевых жанров. Автореф. дис. ... докт. филол. наук. Специальность 10.01.10. - журналистика. / Л.Р. Дускаева. Автореферат диссертации на соискание ученой степени доктора филологических наук. - С.-Пб. 2004. - 26 с.

8. Куликова, Е.В. Графические средства как стилистические приемы художественного текста // Таврический национальный университет им. В.И. Вернандского. - Симферополь. 2000. - С. 6.

9. Мартынова Е.М. Типология явлений коммуникативного дискомфорта в ситуациях диалога. 2000. 229 с.

10. Пешковский А.М. Избранные труды. - М.,1959. - 250 с.

11. Трофимова Ю.М., Свойкин К.Б., Воробьев Ю.К., Злобин А.Н., Фурманова В.П. Анашкина И.А., Седина И.В. Лингвистические и экстралингвистические проблемы коммуникации // Мордовский государственный университет имени Н.П. Огарева. Теоретические и прикладные аспекты. Межвузовский сборник научных трудов. Выпуск 5. - Саранск, 2003. 192 с.

12. Федоренко А.Н. (2017) Продвижение профессионального сообщества с помощью цифровых коммуникаций, https://sfk-mn.ru/PDF/01SFK417.pdf (доступ свободный). - - С.1.

13. Ширяева, Т.А., Авшаров А.Г. Социокогнитивное моделирование как методологическая основа изучения делового дискурса // Общероссийский академический научный журнал «Вопросы когнитивной лингвистики». Выпуск 1, 2018. - С. 94.

14. https:/awwwards.com/

15. https://blog.depositphotos.com/ru/luchshie-dizajni-sajtov-2020.html/

16. https://canva.com/ru/

17. https://deadsign.ru/tipografika/10_tips_on_typography/

18. https://dic.academic.ru

19. https://evolution.depositphotos.com/

20. https://ia.net/topics/the-web-is-all-about-typography-period/

21. https://iamtired.online/

22. https://fb.ru/article/448319/professionalnyie-kommunikatsii/

23. https://fb.ru/article/448319/

24. https://fleava.com/

25. https://kazedu.kz/referat/78941/

26. https://skillbox.ru/media/design/64_sayta_dlya_dizaynerov

27. https://start-luck.ru/dlya-novichka/chto-takoe-veb-sajt.html/

28. https://reclamare.ua/blog 
29. https: //revolution.allbest.ru/marketing/00268098_0.html/

30. https://skillbox.ru/media/design/64_sayta_dlya_dizaynerov

31. https://umom.biz/psihologiya-tsveta-v-marketinge.

32. https://webstudio2u.net/ru/

33. https://ru.wikipedia.org/wiki/Сайт/

34. https://wpsovet.ru/optimizaciya-i-ispravlenie/

( ) Демидова Евгения Владимировна (eva.demidova.85@list.ru).

Журнал «Современная наука: актуальные проблемы теории и практики»

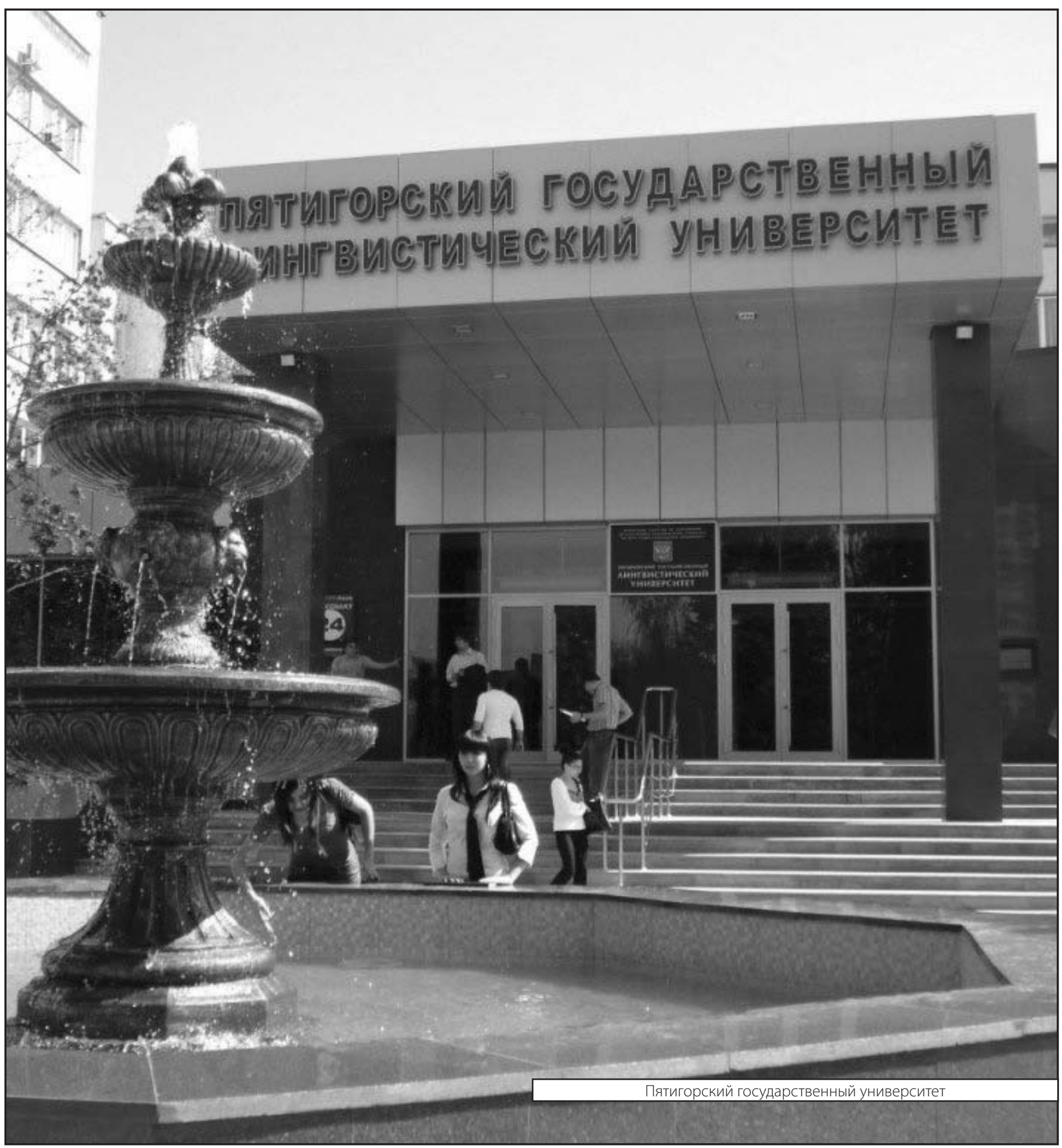

